University of Warwick institutional repository

This paper is made available online in accordance with

publisher policies. Please scroll down to view the document

itself. Please refer to the repository record for this item and our

policy information available from the repository home page for further information.

To see the final version of this paper please visit the publisher's website. Access to the published version may require a subscription.

Authors: $\quad$ Mats Alvesson, Dan Kärreman, Andrew Sturdy and Karen Handley

Title: $\quad$ Unpacking the client(s): Constructions, positions and client-consultant dynamics

Year of 2009

publication:

Link to http://dx.doi.org/10.1016/j.scaman.2009.05.001 published version:

Publisher none statement: 


\title{
UNPACKING THE CLIENT(S): CONSTRUCTIONS, POSITIONS AND CLIENT-CONSULTANT DYNAMICS
}

\begin{abstract}
Research on management consultancy usually emphasizes the role and perspective of the consultants. Whilst important, consultants are only one element in a dynamic relationship involving both consultants and their clients. In much of the literature, the client is neglected, or is assumed to represent a distinct, immutable entity. In this paper, we argue that the client organisation is not uniform but is instead (like organisations generally) a more or less heterogeneous assemblage of actors, interests and inclinations involved in multiple and varied ways in consultancy projects. This paper draws upon three empirical cases and emphasizes three key aspects of clients in the context of consultancy projects: a) client diversity, including, but not limited to diversity arising solely from (pre-)structured contact relations and interests; $b$ ) processes of constructing 'the client' (including negotiation, conflict, and re-construction) and the client identities which are thereby produced; and c) the dynamics of client-consultant relations and how these influence the construction of multiple and perhaps contested client positions and identities.
\end{abstract}

Key words: client, management consultancy, social construction, projects

\section{INTRODUCTION}

What is a client? At one level, the response might seem straightforward - someone who receives help from a professional person. Indeed, this response matches dictionary and everyday definitions. However, even in contexts such as health care and criminal law, where the client is typically an individual, there are often competing perceptions of the client from the different parties involved (Johnson et al, 1995). In corporate and other organisational contexts, such as professional business services, this issue is even more complex (O'Farrell and Moffat, 1991). Indeed, even given minimal sociological imagination, it is possible to see that 
organisations are more or less heterogeneous assemblages of actors, interests and inclinations where conflicts of interests are inescapable (eg Marchington and Vincent, 2004). And yet, 'the client' - in the academic literature on professional services firms and management consultancy in particular - remains largely homogenous and static.

It is therefore important to unpack the nature/s of the client. Indeed, the interests and perspectives of the client have arguably become more important in recent years. The traditional image of the relatively passive or powerless party in the professional-layman interaction is giving way to a hegemonic customer-orientation discourse (Sturdy et al, 2001). Here, representatives of professional service organisations are encouraged to see clients as customers (Du Gay \& Salaman 1992), undermining the notion of client powerlessness, at least on a discursive level. Löwendahl et al (2001) argue that, by definition, professional service firms (PSFs) such as in accounting, law and consultancy, must pay particular attention to client needs and demands whilst they engage in creating customized solutions. Moreover, as PSFs often have a limited number of important clients, and as losing one of them may have significant financial and symbolic consequences, their employees may feel very vulnerable and even appear outwardly subservient to the wishes of the client. As Anderson-Gough et al (2000) demonstrate, a particular discursive construction - 'the demanding client' - is often used as an instrument of socialization in PSFs and thus operates as a form of managerial control. On the other hand of course, traditional dynamics remain relevant whereby PSFs claim to have superior knowledge and are typically hired on that premise. Therefore, they have significant definitional authority on what constitutes a problem for the client and, in many instances, have regulatory authority and closure over client concerns (Löwendahl, 1997).

While some attention has been given to client diversity and dynamics in the traditional professions and, more recently, professional services, in the management consultancy literature, clients have been largely neglected (Hislop, 2002). Clients are typically presented as relatively unitary, organisational entities with attention given to diversity between firms and projects rather than client diversity within them (eg Kitay and Wright, 2004; Werr and Styhre, 2003). Admittedly, there is some acknowledgement of the difference between individual clients who work in teams 
alongside consultants, and other client employees who do not (Czarniawska and Mazza, 2003), implying, for example, that some client actors may be useful for consulting objectives such as knowledge acquisition, whilst others are useful for securing buy-in (Fosstenløkken et al, 2003; Sturdy et al, 2006). Likewise and more generally, the fact that consultancy work is highly interactive and networked (at least for consultancy partners and senior staff) is fairly well established (Alvesson 2004; Jones, 2003). But overall, the myth of the monolithic client remains, and the implications of the potential diversity within client organisations for understanding consultancy practices, processes and outcomes are poorly understood. Organisations remain as super-persons (Czarniawska-Joerges 1994) such that actors become over-determined as organisational or, at best, project-based agents.

This neglect is less evident in the more prescriptive literature on consultancy, often written by consultants themselves. For example, one of the first rules of consultancy practice is to identify the key power brokers and decision makers in a client organisation, especially those with the authority to commission external advisors (Buchanan and Badham, 1999). Similarly and more generally, Arnaud suggests that 'the word client only rarely designates a single unique person' (1998:470), preferring the term 'client system'. More specifically, Schein (1997) adopts a pluralist or, at least, stakeholder view in pointing to six types of clients or client positions. Here, 'intermediate' clients work directly with consultants while the first 'contact' client may differ from the 'primary' owner of the problem. The primary owner is distinct from those 'unwitting'/indirect' clients who are unaware/aware of the effects of the consultancy, and from the more diffuse 'ultimate' client which might include client customers. This categorisation is a useful corrective to much of the more academic literature on consultancy. It serves as a key starting point but is still problematic in that it is rather static, is focused on the consultant's perspective, and is based primarily on contact - from direct to indirect relations - and potential interests. It also understates symbolic and political roles. Here, the academic literature is stronger, pointing to clients using their role with consultants for their own individual, functional or managerial political purposes - legitimation and control - or as scapegoats for failed initiatives (Alvesson and Johansson, 2002; McKenna, 2006; Sturdy, 1997a). However, and as we shall argue, this also presents a partial conception of the client, overemphasizing a fixed role or position. 
In the following analysis, we both draw on and develop the above insights and portrayals of clients in an effort to emphasize:

Client diversity: including, but beyond that arising solely from (pre-)structured contact relations and interests.

Processes of constructing 'the client' (including negotiation, conflict, and re-construction) and the client identities which are thereby produced.

The dynamics of client-consultant relations and how these influence the construction of multiple and perhaps contested client positions and identities.

These concerns suggest an interest, not only in clients, but also in the - frequently multiple and diverse - consultant positions and constructions. We cannot understand clients without considering both parties and their relationship(s). However, given the marginalization of clients in the literature and space limitations we give less attention to the consultant side in order to take a closer look at the client from a set of pluralistic, constructivist and processual viewpoints and address a neglected aspect of the consultant-client relationship. We start by expanding on the three previously-mentioned themes of client diversity, client constructions (and reconstructions) and the dynamics of client-consultant relationships. We then present three diverse case vignettes. We use these primarily to illustrate new ideas and to revise established views through a continued discussion of the key themes. The paper ends with a discussion of some of the implications of our analysis.

\section{TOWARDS THE CLIENT AS CONSTRUCTION}

\section{Client Diversity}

In addressing the diversity of clients, we first need to examine the structured possibilities for difference associated with the client organisation. Firstly, notwithstanding broader socially produced distinctions based on gender, ethnicity, culture and occupation for example, most 
considerations of organisational plurality are based on structured (and associated cultural) divisions between individuals and groups as representatives of particular departments, functions and hierarchical - including managerial - levels (e.g. see Whittington, 1992). Indeed, while many may recognize 'horizontal' employee divisions and the division between management and other employees, it is also important to incorporate divisions within management. This is the agency problem, or what Armstrong (1989) describes as conflicts within capital. In short, one cannot assume that managers are acting in the interest of the organisation or at least not wholly so, even if such an interest can be articulated. Likewise, serving a client CEO or a division head is not necessarily the same as serving the firm, nor is it necessarily a matter of serving a large group of workers or any other group. It is thus important to de-centre and pluralize ideas around the client at even the most basic structural level - to move from client to client positions and their dynamics.

As we have noted, Schein (1997) adopts a different, but related form of structuring, based on a typology of consultant contact and broader structured interests. This is useful as it draws attention to some of the impacts of consulting beyond the client organisation, and incorporates actors' roles that are specific to the consulting context such as client project managers and those who commission the project. But there is a danger of extending the concept too widely for an understanding of consulting practice. Schein's model appears to be so pluralistic as to include the client organization's customers and even wider society. However, and in keeping with many pluralistic accounts, it fails to acknowledge inequalities of power as well as those who might be deliberately excluded from the consultancy process, what might be labeled 'proscribed' clients (Sturdy et al, 2009). Thus, Schein's model assumes that interests can be reconciled in a 'win win' situation. Clearly, this is rarely, if ever the case and we need a more restricted and meaningful notion of a client or plurality of clients. For example, if a client organization's CEO or senior manager wants to cut costs through reducing employee numbers, those targeted for and typically negative to - layoffs are hardly productively conceptualized as a client, as Schein's model would suggest (cf Courpasson, 2000). 
This means that the definition of client(s) and the client interest(s) in consultancy assignments overlooks the conflicts which consultants may produce or are complicit in. Indeed, there may be conflicts between the client(s) and other actors in the client organisation who do not define themselves or are seen by the consultants as 'clients'. Moreover, the varying levels of ambiguity which are inherent in consultancy processes (Alvesson, 2004) further complicate the picture. For example, an interesting situation, for the purposes of this paper, occurs when consultants are given a seemingly clear objective - to cut costs - but vague details. In this case, consultants may be under pressure to act as if all employees are clients (since actual cost-cutting measures are undecided). Likewise, all employees have to act as clients, in terms of positively cooperating and as, at least potentially, benefiting from the consultants' intervention. This changes over time as it becomes clearer who may experience disadvantages as a result of the consultancy and thereby move out of the position or identity as 'clients'. Thus, one would expect client-consultant interaction to be highly ambiguous, precarious and tentative, involving particularly fragile and delicate client and consultant constructions. Here, conflicts can to some extent be understood in terms of who continues to be in a client position and who does not. The latter may see themselves more as targets or victims than beneficiaries.

In addition to seeking to de-limit the notion of client by focusing upon those actors and constructions where (and when) some measure of involvement and agreement is evident or emergent, we must also be sensitive to self- and projected conceptions of the client. For example, where groups of employees, including senior people, are resistant to, or skeptical about, a consultancy project, they are hardly likely to define themselves as clients - or as aligned with the 'generalized' client position of the organisation. They too, therefore fall outside the focal interest of a study of client-consultancy relations, although they of course must be considered as part of the context of such relationships and may even be a target of consultants' constructions of the client. 


\section{Constructing the client: positions and logics}

The idea of client positions refers to how people within the client 'system' are located/locate themselves in different ways in relation to various functions and tasks. This is typically a mix between formal positions, such as project manager, and the active taking (negotiation, maneuvering) of 'identity' positions in the project (e.g. 'thoughtful skeptic', 'radical pusher for change'). These positions reflect some authority and discretion, but also the type and degree of involvement or activity in client work. For example, we are not concerned with the relatively rare cases where clients just employ a consultant, produce a contract and instructions and check that the consultant delivers accordingly. Rather, we focus on the more typical case where client people are actively involved with, and work alongside, consultants.

Here, as with images of consumers more generally (Gabriel and Lang, 1995; Rosenthal et al, 2001), there is a wide variety of positions to take. They include among others the passive consumer, receiving suggestions, analysis and other forms of consulting input; the supervisor, actively directing and controlling consultancy work; the co-worker, cooperating (and/or conflicting) with the consultant in the consultancy process; or the judge, assessing the outcome of the work of the consultant and controlling him/her through feedback and/or a promise (or threat) about re-purchase (Alvesson, 2004).

However, these positions imply a rather static and (internally) monolithic view. Client people can, in practice, adopt multiple positions and/or move between a shared interest and overlapping identification with consultancy people to a more exploitative and instrumental relationship - from colleague to controller. Furthermore, clients - especially perhaps at middle manager level - may experience ambivalence and therefore vacillate between associating themselves with the position of the 'head client' (sponsor, decision maker) or with the operational people trying to deliver, and even with the consultants with whom they work directly. Indeed, the boundaries between consultants and clients - outsiders and insiders - are sometimes blurred as consultants and clients form coalitions or communities, possibly in tension with other parts of the consultant 
and client systems (Czarniawska and Mazza, 2003; Sturdy, et al 2006).

It is important to try and understand the perspectives of the actors themselves - the 'native's' point of view. Even if we delimit interest to those who are broadly supportive or 'pro' the consultancy task, there is a typically space for diversity in terms of having ideas about what and how things should be done. Individuals may, for example, differ in their emphasis of elements such as the delivery of work results, looking good (legitimacy), competence development, advice-giving and giving support to a particular party (typically the dominant one) in power struggles. These are, of course, likely to partially reflect various structured forms of reasoning associated with formal organisational position as noted earlier or, as Schein's (1997) work highlights, project roles. However, as we have suggested, this is both a limited view and an unduly broad one. Overall then, in order to grasp how the client can be unpacked and possible pluralities be detected, we need to consider seriously a) the division of labour within client work and associated positions b) the relations within the client system and c) the differentiated logics of perceiving, valuing and reasoning within groups of client people.

While our focus is on client diversity, similar diversities might also be considered within the consultancy group in a project and we will comment upon this to some extent, not least because it helps construct the client. Indeed, this is consistent with the notion of social construction more generally. Here, the social world is not an objective fact, existing wholly outside the consciousness and languages through which human beings relate to it. In other words, the client logics and positions discussed above are seen as both products and processes and it is important to examine the ways in which the client is (being) constructed. The contrasting view would be that a client is defined as someone with whom a consultant has a working relationship. That this may be the case 'objectively' - legislation and formal, contractual definitions may say so - but not necessarily 'constructionally'. Indeed, phenomenologically and discursively, it is quite an open question. We therefore need to challenge what we formally, theoretically, a priori and often unreflectively see as consultant-client relations in terms of for example, a professional 
giving help to somebody less professional and in need of expert-assistance (Fincham, 1999).

\section{The dynamics of client positions - re/positioning}

Before moving on, we would like to point out that it is difficult to avoid using objectivistic expressions and ideas such as 'consultant-client relations', partly for cognitive reasons, partly because of parsimony. Thus, terms become shortcuts for much longer and complicated representations. If the 'client' people do not see themselves as in need of expert advice, but, say, as competent users and managers of temporary employees, then key characteristics of what is typically associated with the 'client' label are not relevant and the term becomes misleading, 'fixing' what goes on in a problematic way. In other words, one can use expressions like clients in order to simplify and give some hints about what one refers to, but this risks oversimplification and reification and encourages non-constructivist insensitivity. We hope the reader bears this in mind when reading this text.

As argued earlier, client identities and constructions evolve through negotiation and conflict among different actors as they seek to position themselves and others in different ways. Given our focus on client construction, we are interested in the more careful appreciation of what is happening with the idea of 'the client' in a more processual, non-linear and context-sensitive way. We can assume that, at least within an assignment lasting more than a brief time period, there is a variety of actors and groups ascribed with and taking various client positions. Furthermore, within a complex assignment, there are likely to be actors and groups within the client firm that identify with the project and their client positions, people that are skeptical or hostile and those who are ambivalent. Furthermore and as noted above, people may also shift positions - especially those who are ambivalent. The implication of this is that there may be people who occasionally see themselves as client-representatives, sometimes not. They may sometimes identify with the consultants, sometimes not. This can, to some extent, be conceptualized through social identity theory (eg see Ashforth \& Mael 1989; Haslam, 2004; 
Turner, 1984), but moved into a more processual direction, emphasizing the shifting identifications and 'we's' and 'they's' that presumably characterize people involved in complex social interactions where different social categories are present (e.g. project members, divisions, professions, firm, age, etc). When considered in a dynamic context, we can begin to see client diversity and client constructions in a processual and context-changing perspective, by looking at client positions, not as fixed within a project, but as positionings and re-positionings. A key question here is 'when is a client a client?' i.e. when do actors construct themselves and others as a client in a conventional sense (i.e. somebody in need of the service from a more knowledgeable professional) and how is this done?

\section{THREE EMPIRICAL ILLUSTRATIONS}

We have outlined three related themes which we argue are important to an understanding of consultant-client relations, and especially the neglected side of management consultancy - the client. We now present three illustrations or vignettes of clients in management consultancy work. These vignettes illuminate different aspects of our three themes. Example Alpha will mainly address our first theme of client positions and logics; Example Beta is primarily concerned with constructions; while Example Gamma is used to illustrate the dynamics of clientconsultant relationships. All cases have something to say about the other themes and we will draw out some ideas through comparing different issues in the examples.

The three vignettes are drawn from three research projects on client-consultancy relationships and differ in their research settings. Drawing upon different research projects is methodologically rather unconventional, although each project had a similar focus. We argue that by combining insights, it is possible to consider a broader range of dimensions around clients which means that interpretations can be made on the basis of wider and deeper research in the particular contexts. The first example (Alpha) is based on interviews with different actors - three consultants and four client managers - directly involved in a consulting project about their perceptions of the project and its results. Beta is based on observation of an internal project 
review meeting at a large transnational consulting firm as part of a four year longitudinal study of the firm. The final example, Gamma, is based on an in depth ethnographic, fly-on-the-wall study of a consulting project, observing client-consultant interactions as well as interviewing participants over a 6 month period.

Both individually and collectively, the vignettes provide rare data in a field where research access is notoriously difficult to achieve (Sturdy et al, 2006). However, we are also modest about claims that can be made from the data. We use the examples and data from them selectively, as vignettes rather than as full cases (eg see Carlile, 2004), and seek to generate insights which may be of value to readers in making sense of other, similar situations. Furthermore, and in keeping with post-empiricist trends in methodology and the philosophy of science, we are neither seeking nor claiming non-ambiguous truths (Alvesson \& Sköldberg 2000; Denzin \& Lincoln 2005).

\section{Alpha: Exploring Client Positions}

In this consulting project, the consultancy firm was a very large management consultancy, Big Consulting $(\mathrm{BC})$, specializing in the implementation of major change programmes. The project was a two-year assignment aimed at the rationalization of support services at the client organisation, High Tech $(\mathrm{HT})$, another large multinational firm. HT was the outcome of a recent merger, and the consulting project was triggered by this and the associated ambition to cut costs. According to internal project documents, the aims included creating a 'high quality and professional service' at a competitive cost within HT. This would make it possible for local site management to focus on the 'core business' and also give (remaining) service personnel a 'challenging and stimulating place to work'.

In the project we identified a range of client positions, but three were especially distinct and dominant. They broadly follow formal organisational and project roles, in keeping with Schein (1997), and this positioning partly informs their own perspectives or logics. However, we shall 
see that further complexities are evident, especially in relation to how they see the project and its outcomes.

The client firm employees working operationally on the change project mainly focused on delivery of specific results associated with the implementation of new standards and practices. They saw themselves very much in a relationship with consultants where it was vital to get results and resources and to focus on production. Thus, they fit our delimited notion of clients. However, the situation was far from tension-free as junior client managers saw the consultants in a negative light, as insufficiently willing and able to create specific results

'I think that BC thinks in terms of concepts, about whether or not a concept is a good one for them. .... They've been sitting around a bit too much thinking conceptual thoughts about how it could work, but they haven't gone out and actively got things done in the business.' (Client project team member)

Given such concerns, these client personnel saw their role as supervisors, taking an active and powerful part in making consultants produce.

The senior client project manager also worked fairly closely with the consultants and the other client project team members. One might expect his position to be similar to the latter group given his formal role as project manager, but this was not entirely the case. He saw himself as a receiver of support (i.e. as a client in the more conventional sense) and expressed a quite different, more positive, view of the consultants:

'I feel that we benefited very much from BC, thanks to their competence and their computer media skills. When working with an old guy like me, who has lived four generations too early in terms of computers, then there's no chance of making things work if you don't have employees from BC, who are excellent with computers.' 
The client project manager thus emphasized a seemingly more personal concern - the consultants' role in helping him with computer issues in a sensitive way to save him from embarrassment. This concern, combined with his own exposure as the person who commissioned and managed the project, might have informed his subsequent assessment of the consultants overall. Here, despite the project failing to realize many of its formal objectives, no blame was attributed to the consultants. As the project progressed, the client project manager appeared gradually to downplay the significance of specific results and to emphasize instead the consultants' political or rhetorical skills in impressing top management through their reports, plans and presentations.

'Some things (from the project) have been accomplished, but not all we expected. ... We calculated what we thought it (cost savings) would amount to. But then it became diluted and I don't know what became of all the billions we would save. But what has come out of this are the presentations that Farringdon (senior consultant) and Blake (executive in the client firm) gave to (Head Office) management ..... After what we've done, everybody (there) thought that this was an amazingly good and well-accomplished project.' (Client project manager)

Overall, he saw the project as successful based on establishing a smooth working relationship with the consultants (seeing the parties in the relationship as complementary, junior co-workers), but also, crucially, because top management seemed very satisfied - a source of some personal relief. The client project manager's view about making top management happy was shared by the senior consultant:

'Personally it feels like the project has been good. We have really established ourselves as advisers, especially for Blake and Mueller (executives in HT) but also for other 
managers.'

While for junior client managers, the work of the consultants were seen as unsuccessful, for senior management what seemed to matter most were appearances and future prospects. This might be seen as a reflection of superficiality on the part of senior management in terms of not recognizing the failure to realize cost savings and other objectives. However, the broader context is important in that the change project was triggered not simply by the merger, but by a specific promise to investors and the stock market of substantial savings in the future. Hope and expectations mattered more than actual delivery.

\section{Beta: Constructing client positions}

In this case we draw from field notes recorded at a 'competence group meeting' in a multinational consulting firm, Topconsulting. This was an event where consultants met to discuss, reflect upon and learn from previous experiences. The excerpts are taken from a presentation about a recent successful project with a client, CarCo.

Fred, the senior consultant that presents the case, quickly briefs participants on the project's current status. BCD - the unit in question, a subsidy to CarCo, a car company - has experienced dramatic downsizing among blue-collar workers (from 4700 to 2700 ). However, white-collar headcount has not changed. So, the client management felt that there was 'fat to trim' and decided to spend a day together to identify cost cutting measures. However, the meeting only lasted two hours before it ended up in deadlock. After that, they asked Topconsulting for help. In response to a direct question Fred thinks that the reason they asked Topconsulting was because of their presence in Smalltown (the local area) and experience with CarCo. "It was an interesting opportunity. We were granted freedom to set up the organization in any way we wanted, within the boundaries of the project."

In many ways, this situation reflected a common situation in consultancy. The firm was offered the job because they had had previous engagements with the client - at least, that was what the 
consultants thought themselves. The task had a fairly specific objective: to downsize and cut costs. It was also relatively short on details. In fact, when management tried to work out the details, they became stuck and hence asked for help from the consultancy firm.

Fred moves on to what he felt was problematic in the project. "Smalltown is a single company town. The management has worked there forever. I think that the board of directors has 320 years of experience combined. They are very competent, but it is hard to make them customer-oriented. Everything centres around the factory. And everything is decentralized so there is hardly any co-ordination. That's a problem because everybody is just thinking from the perspective of their department or factory. But the main problem is geographical - Smalltown is in the middle of nowhere."

Interestingly, the problem here according to Fred was not the entrenched interests of factory managers and the politics of special interests. The problem was rather that the client was too amorphous to function as a speaking partner. Nobody claimed or had sufficient authority to claim successfully to represent client interests, at least not as understood by the consultants.

Fred continues describing the work processes of the consultants and focuses on how they persuaded management to participate in developing and accepting the plans: "We had a half day workshop every week with the board, the same board that couldn't cope with two hours the first time. So, on the first workshop we introduced rules, like in football, to guarantee that they operated as a group instead of as representing departments and factories. We implemented a system with yellow cards and red cards. Three yellow cards meant that they were dismissed from the workshop. It worked. They started to function as group. We encouraged them to see themselves as a consulting branch. They even called themselves BCD Consulting.

The consultants here actively engaged in creating and constructing what they perceived to be an 'appropriate client'. They claimed to have put senior officials into a situation where they were 
more or less forced to operate as a group. The demands of the task meant framing the client position so that it shaped the factory managers' degrees of freedom. The consultants' view was that the task demanded a unitary body that transcended the narrow interests of factory and departmental managers and that could respond, at least temporarily, straightforwardly to the concerns and issues that the task created. The consultants demanded a functional body with which they could interact on an everyday basis. From a rhetorical and dramaturgical point of view, it is also interesting to note how a sporting metaphor was used to create and enforce a unitary client position. The consultants constructed the situation so that they operated as referees, awarding penalties for non-constructive conduct, thus subtly framing the construction of a unitary client position as legitimate, necessary, and fair, simultaneously presenting the position itself as legitimate, necessary, and fair.

The final excerpt introduces different and quickly-shifting qualities of the client as constructed by the consultants as well as a more pluralistic perspective echoing Schein's (1997) framework outlined earlier.

Fred then presents Topconsulting's specific proposal for organizational change. This includes the names of the client people who will be offered managerial positions. The names fuel a discussion among the participants who all seem to be familiar with senior CarCo personnel. The comments, while mostly anecdotal, seem to suggest pride or showing off in terms of having deeply layered relations with key clients. After a while, the presentation moves on to the implementation stage. Here the trade union appears for the first time. Fred pronounces it with a capital $U$ and with a body language that signifies uncertainty and some consternation. "What are we going to do with the union? At first, we hesitated. There was a fear that they would co-opt the whole thing and turn everything into negotiations. But that never happened. It was almost the reverse. They were the driving force in the implementation stage".

Fred wraps up his presentation with a summary of the proposal in quantitative terms: "The 
board goes from 9 to 10 . We eliminate 32 middle management positions. And so on. In total, we cut 220 positions which translates into 150 million SEK." Finally Andy asks about the lessons learned in the project. "The project is similar to many other projects from a work perspective. So no lessons learned there. The most important lessons were in the interaction with the board, in making it work. That was both fun and a learning experience."

Here we see a suggestion of the importance of relatively intimate connectedness with clients and a familiarity which goes beyond what is motivated by a single project. In this sense, the consultants engaged in creating potential templates for future client constructions that included an understanding of who was moving to which position within the client organization. This combined clients as personal connections with a more 'objective' and rational view of the client as a formal organisation. Finally, the excerpt also points to the scope of resources potentially available for consultants in shaping and maintaining preferred client positions. In this case, somewhat unexpectedly, the union became a helpful client-as-partner as a driving force behind the implementation.

\section{Gamma: constructing dynamic client positions}

In this example, the consultant was an individual freelancer working as an 'Associate' for a consulting network organisation. The consulting project was a six month assignment to provide project management advice/mentoring, quality assurance (legitimation) and knowledge transfer to a project team working in a small 'failing' prison. The client's project was to prepare and present to an inspection team a bid which reported on and planned service standards. If the bid had failed, management of the prison could have been put out to tender in the private sector. In the event, it succeeded. However and as in Alpha, views of the value of the consultant's contribution were mixed and context-specific. At the same time, the example is effectively one of a project (i.e. consultancy support for the client) within another project (i.e. to construct the bid) and illustrates some of the possible complexity over identifying clients as well as the dynamics and variety of client positions and orientations. 
The bid process was set up by the national Prison Service who appointed a project manager (PM) and assistant (APM) from a cadre of young Head Office 'fast track' civil servants, both recent MBA graduates. The PM was responsible for the bid process and presentation and also for the contract with the consultant. In Schein's (1997) terms, he was both the contact and primary client and met regularly with the consultant in often lengthy meetings sometimes additionally with the APM and others. At the same time, the prison Governor was directly accountable for the outcome of the bid. He had occasional meetings with the consultant, mostly alongside the PM. However, to the consultant, it was the Governor or even 'the prison' which was the true client or - in Schein's terms - the ultimate client. Indeed, to an extent, the Governor also saw himself in this way, seeing the role of the PM as an 'external' resource, an internal consultant even, there to free up his time.

At one point, this ambiguity over the identity of the client resulted in overt conflict. The consultant attempted to construct the Governor as a legitimate client by contacting and meeting him, partly with a view to generating follow-on business. When the PM found out that this had happened without his prior knowledge or agreement, he was, according to his own account, 'very pissed off'. He felt that the consultant had betrayed their relationship and challenged his authority and status as the client, as a representative of head office and as the budget holder. After confronting the consultant about this late one night on the phone, the consultant, according to the PM, immediately gave way, keen not to threaten the relationship (and future business) with him - 'He just kept saying sorry; he didn't even try to explain his actions'. Thus, the PM reasserted his own position as the client in control although once the project was completed, the consultant once again approached the Governor, albeit with no success in terms of new business.

Throughout the project, but especially in its early stages, the PM and APM sought to present or assert an identity of themselves as 'competent clients'. The PM in particular was acutely aware that he had no prior experience of dealing with consultants, and was not sure how things 'should be done'. At the same time, the consultant represented a luxury or source of prestige to him although his presumption that he should be a receiver of expertise was hampered by the 
realization that the consultant's project management experience was from an 'alien' sector (private engineering rather than public sector services). At first, the PM and APM responded by reframing their position as mediators between the consultant and the rest of the project team. They felt able to translate the engineering language with the benefit of their head-office sponsored MBA education, which the prison staff did not have.

APM: 'What we end up doing is kind of bridging some of that gap, to some degree, trying to interpret and put some of the learning that we've gained from [the consultant] back into prison service language really..... And I think that's worked reasonably well.'

This shift contributed to the junior staff on the project ceasing to become clients. Part of the consultant's formal brief was to coach the project group (mostly made up of prison people involved on a part-time basis). He started this with a presentation and training, and junior client staff seemed to value it. However, he was soon effectively prevented from continuing to work directly with these clients as the PM saw the consultant's time as being best used in small advisory meetings with him and, to a lesser extent, the APM and/or more senior (non project) staff. The PM's enjoyment of the luxury of consultancy mixed with concern about his alien language, as well as the lack of resources - all contributed to this repositioning of himself, the consultant and the rest of the project team.

Gradually, however, through long hours of working together and using boundary objects such as a project management software package, the PM and consultant came to appreciate each others' skills and contributions to the project. The PM saw the consultant as a competent and well intentioned coach and mentor, genuinely committed to a successful bid. However, the shifting position of the PM and his increasingly 'cosy' relationship with the consultant had implications for his relations and influence with other project staff. As one team member said towards the end of the project - 'we see you (the PM, APM and consultant) as distant cousins' (i.e. no longer completely one of us). 


\section{DISCUSSION}

Each of the above examples has been presented in a way which emphasizes an important feature of the notion of a client - positions and logics, constructions and dynamics. However, before discussing each in turn and by way of a summary, it is worth briefly showing how all three themes are evident more generally (see Table 1). For example, while different client positions clearly emerge in Alpha between being production-focused and image-focused, one can also see different constructions of clients - the project manager moves towards a more political, and less technical, assessment of the project success. In Beta, attention is focused on the client as a unitary body and other constructions, but the client position as uncertain and the move towards becoming more compliant to consultant recommendations are also evident. Similarly, while Gamma sets out the client PM's shift from a consumer of what he sees as luxury goods towards being more controlling and then collegiate as well as other dynamics, a range of client positions and constructions can also be seen to emerge. For example, the PM and APM came to view themselves as knowledge mediators between the consultant and other team members. 
Table 1 - Summary of Examples and Client Themes

\begin{tabular}{|l|l|l|l|}
\hline Alpha & $\begin{array}{l}\text { Client positions and } \\
\text { logics }\end{array}$ & $\begin{array}{l}\text { Constructions of } \\
\text { clients }\end{array}$ & $\begin{array}{l}\text { Dynamics of } \\
\text { consultant-client } \\
\text { relations }\end{array}$ \\
\hline Beta $\square$ & $\begin{array}{l}\text { Production v image v } \\
\text { intermediate }\end{array}$ & $\begin{array}{l}\text { As technologically } \\
\text { naïve; as skeptical of } \\
\text { concepts; as } \\
\text { consumer of } \\
\text { presentations, as } \\
\text { harsh foreman }\end{array}$ & $\begin{array}{l}\text { PM becomes less } \\
\text { focused on } \\
\text { quantitative results } \\
\text { and more } \\
\text { political'/image- } \\
\text { conscious }\end{array}$ \\
\hline Gamma & $\begin{array}{l}\text { Uncertain - buyer of } \\
\text { decisiveness }\end{array}$ & $\begin{array}{l}\text { As players in a } \\
\text { unitary game with } \\
\text { rules; as future clients } \\
\text { and consulting } \\
\text { objects/targets }\end{array}$ & $\begin{array}{l}\text { Team becomes more } \\
\text { unified, compliant to } \\
\text { consulting method } \\
\text { and then divides. }\end{array}$ \\
\hline & $\begin{array}{l}\text { Student-reflector, } \\
\text { controller, internal } \\
\text { consultant }\end{array}$ & $\begin{array}{l}\text { Develop as } \\
\text { knowledge } \\
\text { mediators; contested } \\
\text { status as primary } \\
\text { client }\end{array}$ & $\begin{array}{l}\text { From consumer of } \\
\text { luxury goods to } \\
\text { controller to } \\
\text { colleague and being } \\
\text { mentored }\end{array}$ \\
\hline
\end{tabular}

Taking each of the illustrations in turn, it is clear from Alpha how important it is for consultants to read client positions and logics and even to seek to anticipate variability in them. The client preference for good presentations about prospects is quite different from that of wanting delivery of cost savings: a good PowerPoint presentation may be a sign of competence and/or a largely irrelevant performance. To an extent and as noted earlier, the need to navigate between such client preferences and positions is a central element of consultancy practice, illustrated in formal or informal techniques of power mapping (Buchanan and Badham, 1999; Sturdy, 2006). However, this imperative is rarely explicit in the literature on consultancy or client practice where the politics of change management seem to have been lost in presumed unitary assumptions (or, exceptionally, a 'neutral' pluralism of client roles) and the apparent rationality of project management techniques for example. Thus, clients too, need to read their own politics of consultancy interventions as well as other positions.

The example also appears to reflect a case of 'real' (or at least, original) criteria for assessing 
success being subsumed by superficiality and politics - with the senior participants coming to emphasize persuasive presentations and a favorable impression with client top management. Here, for the consultants, if top management is happy, then one's own career and future consultancy sales possibilities appear to be in order. Happy (senior) clients are what count while what is accomplished 'substantively' may matter less, however skeptical other client team members appear to be. However, at Alpha even these other clients acknowledged the consultants' skills in making presentations; the point is that they saw little value in it. Indeed, it is seen to detract from the 'real' issue of delivering practical and concrete results. It thus seems to be a question of contrasting interpretive logics founded on hierarchical and functional positions and reinforcing the view that, in management, symbolic logics typically hold sway over substantive logics (Jackall, 1988) and that consultancy is therefore, largely a question of impression management and rhetoric (Alvesson, 2004).

However, different interpretations are possible. For example, the skepticism of more junior client employees might also reflect the threat that consultants pose to their own expertise (Sturdy, 1997b) while senior participants' concerns with presentation and image is in keeping with a practical and 'concrete' concern with the importance of shaping expectations of shareholders that 'something is being done'. Symbolism has a financial value (Tengblad, 2004). At the same time, the consultants' logics (and dynamics) should also be taken into account and this gives rise to a different reading. Big Consultancy is especially well known for skills and reliability in delivering results. Internally they talk about a 'delivery culture' and interviewees refer to very long working hours and a sometimes extreme pressure to deliver on time. In this project, the problems of doing so probably led to a gradual shift of focus from client-representatives involved in production to client-representatives as consumers of plans and prospects. Furthermore, this fits with more general consultant concerns with securing senior 'buy-in' at the start of a project, junior client compliance to help ensure completion, and senior level commitment to opportunities for new business (Sturdy, 1997b). 
One interesting difference between Alpha and Beta is what we might describe as a honing out versus honing in of the client. In Alpha we present a fairly clear and persistent cut off between different client positions and logics, between a production discourse and persuasive talk (Meyer and Rowan, 1977). In Beta, while similar divisions were partially evident, we focus on the efforts of the consultants to reduce the diversity of leading actors within the client company. Here the client is 'honed in' on and constructed by the consultants in a discursive and sense making project. Thus, while Alpha demonstrates the plurality of client positions and its effects on clientconsultant relationships, Beta illustrates that the client position can be precarious and informed by active construction by other parties such as the consultants. The consultants' influencing tactics may differentiate and separate different client targets or try to unify various actors, 'dedifferentiating' them into a client body.

In particular, Beta demonstrates three main points about the construction of clients and client positions. First, it is clear that consultants have a strong preference towards working with one coherent and unitary client. It is also clear that this client cannot only exist as an abstraction: it has to exist as a manifest body that consultants can interact with more or less in an everyday fashion. Such a client position is probably a rare beast, at least in large bureaucracies, where diverging interests and mind-sets tend to fragment client positions. In the Beta case, the fragmentation is so strong that nobody can speak as the client. This is clearly a problem for the consultants. Client-consultant interaction demands consultants and clients. If the client is too amorphous and diverse, there is nothing to interact with, except perhaps in the most hierarchical of contexts.

In Beta, the consultants respond by working towards creating a client position that corresponds to their needs. This brings us to our second point. The case indicates that consultants may engage actively in the construction of client positions. Typically, client organizations can be expected to be populated by a variety of client positions, some who might be strongly institutionalized, and some who have a more fleeting and temporary appearance. The case 
shows that it would be a mistake to underestimate the importance of more temporary and fleeting client positions. According to the consultants, it was the successful construction of the client position that enabled the project to move forward. In fact, this type of client construction work may be a recurring and important part of consultancy.

Third, the case indicates that the resources for constructing, maintaining and enforcing client positions may have a fluid and dynamic character. Sometimes such construction work invites strange bedfellows. In the case above, the union became a change agent, and a resource for the consultants to maintain a coherent client position to interact with. At a first glance, this may be unexpected and surprising. Typically, consultants would view managers as potential friends and union representatives as potential foes. However, reversals may be perfectly reasonable. Consultant intervention may hurt some manager's short-term interests (which may affect remuneration and career prospects) whilst also strengthening the company's long-term prospects (which of course affects union members job security). Thus, the construction of client positions is embedded in contextually determined enablers and disablers, where we can expect consultants to take active part in the construction work (Sturdy, 1997b).

In Gamma too, the consultant is involved in client construction (and deconstruction) as is evident in his efforts to engage the prison Governor as 'the natural client' while by-passing the one who defines himself as the principal client. It is interesting, if not surprising, however, that the consultant does not seek to construct the PM (or the Governor) as a more professional manager of consulting projects despite his project management expertise. Nor was this evident in the other cases. But what is especially evident from this example are the diversity and, in particular, dynamics in client/consultant relations positioning as well as constructions. Consider for example the unfolding of the relationship between the consultant and the project team. The full time members of the project team initially saw the consultant as a source of project management expertise and seemed to relish the opportunity to learn about project working. They also saw themselves as translators or mediators of technical language for the other prison staff not 
working in the project team. However, their initial positivity about dealing with the consultant was cut short as their contact with him - and client position - fell away. Those more senior client participants, such as the Governor, were preoccupied with the outcome of the bid and saw the consultant in a relatively marginal role, almost as a mentor to the PM who himself was seen as more of an internal consultant than a Prison Service colleague, especially towards the end of the project.

The relationship between the PM and the consultant was quite formal and distant at the start of the project. Combined with inter-personal tensions associated with their contrasting backgrounds or logics, the PM was enjoying the status of having what, in this particular sector, was considered a luxury - consultancy support. The consultant sought to construct the PM as a learner of project management and as a colleague through his interpersonal style of persistent questioning combined with self-effacement and humour. As the project came to a conclusion however, both the consultant and the PM became quite marginalised both from the broader project and each other. Thus, the example illustrates some of the dynamics of client positioning, but also ambiguity and plurality, in this instance in terms of an individual rather than the more conventional view of different client groups. For example, we have a situation where client positions include that of the conventional role of learner or someone being coached (PM and, initially, project team); a privileged actor enjoying and having to protect the heightened status and extra resource; being marginalised as the project progresses (team and, then PM); a purchaser of expertise with a concern for value for money (Head Office); a sector/organisational insider who is sceptical of the alien nature of consultant discourse, and; a co-worker, separated from the other participants and joined together out of a shared sense of ownership and dedication. Here then, we see not only the dynamics of client positions, but further diversity in client positions and constructions.

\section{CONCLUSION}

We have suggested that although the management consultancy literature frequently mentions the central role of the client in understanding consultancy processes, the client role is rarely 
elaborated. We argue that the client and client construction processes are important and we suggest that where 'the client' is addressed in the literature, there is an inclination to conceptualize it as a static, pre-structured entity, a monolith, either as an organisation with shared interests or an actor representing such organisations. A few studies have pointed to variations between clients and projects and, in particular, between project teams and other employees in the client system. For example, Schein (1997) presented a structured framework of clients, comprising varying levels of consultancy contact/impact and project responsibility. We have sought to develop these ideas towards a view of clients as relational, pluralistic, processual and constructed. We suggest that taking concepts such as multiplicity, interactivity and fluidity seriously may contribute to a richer view of management consultancy. This implies a problematisation of ideas of the client and opening up the empirical variations behind what is obscured by terms like clients and client-orientation.

Client position plurality is important to understand because it shapes the ways consultants and clients interact. Client positions also strongly affect the kind of input, information and access consultants may expect, as well as criteria for performance. Client position plurality may also be expected in most organisations, where actual positions and their permanence are shaped not only by functional position or job role within the consulting project (cf Schein, 1997), but also by a range of possible and sometimes shifting cultural, institutional and personal factors.

Our analysis of client position dynamics provides cues to understanding how client-consultant relationships are developed, maintained and/or threatened, particularly in relation to the social and political processes. Socio-political processes highlight the importance of 'thickening' the relationship and lubricating it to establish and maintain degrees of trust that may substitute (or obscure) more direct forms of control and facilitate project completion and future business contacts. At the same time, they illuminate how power relationships play out between clientconsultant and client-client, such as obscuring the brute application of sovereign power, but also more subtle processes of marginalization, as illustrated in Gamma. The process aspect of client- 
consultant projects also includes how representatives of various subject positions may be more or less salient in various stages of the project and how the subject positions may change.

Our discussion of the construction of client positions also casts light on their origins and how they can be reconstructed. As the examples demonstrate, both clients and consultants may influence client position construction. Client position construction may be fed from a multitude of sources, such as organisational politics and other intra-organizational (but societal) structural, cultural, and institutional factors, and need not always follow the traditional view of consulting rhetoric whereby clients are constructed as 'in need of expert advice'. Indeed, (self) identity positioning is also relevant since clients also construct themselves based on their own experience and reflections.

We have highlighted some of the key aspects of the multiplicity of client positions and their continual reconstruction by clients, consultants and other actors. These aspects may concern changing power dynamics, changes to the access allowed to (or granted from) clients, and so on. For example, as shown in Gamma, the client project manager's growing association with the external consultant, his anxieties over project progress and the alien nature of the consultant's expertise meant that the other client team members came to see him as a 'distant cousin' - no longer 'one of us' and therefore not fully in tune with staff concerns and issues more broadly. Clearly, popular discourses around client-orientation need to be opened up further as they imply the existence of a single and fairly fixed reference point and that clients will behave in a 'clientlike' manner.

While this article has raised some questions about the client side of consultancy, implications for further research also concern consultants, as well as the relationship and interactions of consultants and clients. Apart from more work of a similar kind on clients, we think it is important to study consultants and how they are constructed by clients and in their own backstage selfconstructions. The idea here is not to continue the privileging of consultants as the key actor in 
management consultancy, but to see them as constructed in the context of active clients. A more interactive and relational approach can also address various actors without necessarily privileging any one of them. An important task for further research is to explore the variety of consultant and client positions and constructions, and to investigate how these are produced interactively over the duration of projects and longer-term relationships. This research will have implications for the development of practices by both consultants and clients.

\section{REFERENCES}

Alvesson, M. (2004). Knowledge Work and Knowledge-Intensive Firms. Oxford: Oxford University Press

Alvesson, M. \& Johansson, A.W. (2002). Professionalism and Politics in Management Consultancy Work. In R. Fincham \& T. Clark (Eds.), Critical Consulting: New Perspectives on the Management Advice Industry. Oxford: Blackwell.

Alvesson, M. \& Sköldberg, K. (2000). Reflexive Methodology. London: Sage.

Andersson-Gough, F., Grey, C. \& Robson, K. (2000). In the name of the client: the service ethic in two professional service firms. Human Relations 53(9), 1151-1173.

Armstrong, P. (1989). Management Labour Process and Agency. Work Employment and Society, 3(3), 307-322.

Arnaud, G. (1998). The Obscure Object of Demand in Consultancy - A Psychoanalytic

Perspective. Journal of Managerial Psychology, 13(7), 469-484.

Ashforth, B. \& Mael, F. (1989). Social Identity Theory and the Organisation. Academy of Management Review, 14, 20-39.

Buchanan, D. \& Badham, R. (1999). Politics and Organizational Change: The Lived Experience. Human Relations, 52(5), 609-629.

Carlile, P. R. (2004). Transferring, Translating and Transforming: An Integrative Framework for managing Knowledge Across Boundaries. Organization Science, 15(5), 555-568.

Courpasson, D. (2000). Managerial Strategies of Domination - Power in Soft Bureaucracies. Organization Studies, 21(1), 141-161.

Czarniawska-Joerges, B. (1994). Organization and identity. In S. Deetz (Ed.) Communication Yearbook 14. Newbury Park: Sage Czarniawska, B. and Mazza, C. (2003). Consulting as Liminal Space. Human Relations, 56(3), 267-290.

Denzin, N. \& Lincoln, Y. (Eds.) (2005). The SAGE Handbook of Qualitative Research, (3 ${ }^{\text {rd }}$ edn.) London: Sage Publications.

Du Gay, P. and Salaman, G. (1992). The Cult(ure) of the Customer. Journal of Management Studies 29(5), 615-633.

Fincham, R. (1999). The Consultant-Client Relationship - Critical Perspectives on the Management of Organisational Change. Journal of Management Studies, 36(3), 335-351.

Fosstenlokken, S. M., Lowendahl, B. R. \& Revang, O. (2003). Knowledge Development Through Client Interaction - A Comparative Study. Organization Studies, 24(6), 859-880.

Gabriel, Y. \& Lang, T. (1995). The Unmanageable Consumer - Contemporary Consumption and its Fragmentations. London: Sage.

Haslam, A. (2004). Psychology of Organizations (2nd edn.). London: Sage 
Hislop, D. (2002). The Client Role in Consultancy Relations During the Appropriation of Technological Innovations. Research Policy, 31, 657-671.

Jackall, R. (1988). Moral Mazes. New York: Oxford University Press

Johnson, T., Larkin, G. and Saks M. (1995). Health professions and the state in Europe. London:

Routledge

Jones, A. (2003). Management Consultancy and Banking in an Era of Globalization.

Houndsmills: Palgrave/Macmillan.

Kitay, J. \& Wright, C. (2004). Take the Money and Run? Organisational Boundaries and

Consultants' Roles. Service Industries Journal, 24(3), 1-19.

Lowendahl, B. (1997). Strategic Management in Professional Service Firms. Copenhagen:

Copenhagen Business School Press.

Løwendahl, B., Ø. Revang \& Fosstenløkken, S. (2001). Knowledge and value creation in professional service firms: A framework. Human Relations 54, 911-931.

Marchington, M. \& Vincent, S. (2004). Analysing the Influence of Institutional, Organisational and inter-personal forces in shaping inter-organisational relations. Journal of Management Studies, 41(6), 1029-1056.

McKenna, C. (2006). The World's Newest Profession. Cambridge: Cambridge University Press.

Meyer, J. W. \& Rowan, B. (1977). Institutionalized Organizations: Formal Structure as Myth and Ceremony. In M. Zey-Ferrell \& M. Aiken. (Eds.), Complex Organizations: Critical Perspectives.

Glenview: Scott, Foresman

O'Farrell, P. N. \& Moffat, L. A. R. (1991). An Interaction Model of Business Service Production and Consumption. British Journal of Management, 2, 205-221.

Rosenthal, P., Peccei, R. and Hill, S. (2001). Academic Discourses of the Customer -

"Sovereign Beings", "Management Accomplices" or "People Like Us"?. In A. Sturdy, I. Grugulis \& H. Willmott (Eds.), Customer Service - Empowerment and Entrapment. Basingstoke: Palgrave/ Macmillan.

Schein, E. (1997). The Concept of "Client" From a Process Consultation Perspective: A Guide for Change Agents. Journal of Organizational Change Management, 10(3), 202-216.

Sturdy, A. J. (1997a). The Dialectics of Consultancy. Critical Perspectives on Accounting, 8(5), 511-535.

Sturdy, A. J. (1997b). The Consultancy Process - An Insecure Business? Journal of Management Studies, 34(3), 389-413.

Sturdy, A J., Clark, T., Fincham, R. and Handley, K. (2009) 'Between innovation and legitimation - Boundaries andknowledge flow in management consultancy', Organization, forthcoming

Sturdy, A. J., Grugulis, I. \& Willmott, H. (2001). Customer Service - Empowerment and Entrapment. Basingstoke: Palgrave/ Macmillan.

Sturdy, A. J., Schwarz, M. \& Spicer, A. (2006). Guess Who's Coming to Dinner? Structures and Uses of Liminality in Strategic Management Consultancy. Human Relations, 59(7), 929-960.

Tengblad, S. (2004). Expectations of Alignment: Examining the Link between Financial Markets and Managerial Work. Organization Studies, 25(4), 583-606.

Turner, J. (1984). Social Identification and Psychological Group Formation. In H. Tajfel, (Ed.), The Social Dimension. Vol. 2. Cambridge: Cambridge University Press.

Werr, A. \& Styhre, A. (2003). Management Consultants - Friend or Foe? Understanding the Ambiguous Client-Consultant Relationship. International Studies of Management and Organization, 32(4), 43-66.

Whittington, R. (1992). Putting Giddens Into Action. Journal of Management Studies, 29(4), 693712. 
FILENAME $\quad \backslash *$ MERGEFORMAT ClientpositionsSJMfinalII.doc PAGE 5 